\title{
PENGGUNAAN METODE STATIS DAN LIVE FORENSIK PADA UAV UNTUK MENDAPATKAN BUKTI DIGITAL
}

\author{
Ibnu Fajar ${ }^{1}$, Dhomas Hatta Fudholi ${ }^{2}$, Yudi Prayudi ${ }^{3}$ \\ 116917209@students.uii.ac.id, hatta.fudholi@uii.ac.id, prayudi@uii.ac.id \\ 1,2,3 Universitas Islam Indonesia
}

\begin{abstract}
Abstrak
Dalam beberapa tahun terakhir, penggunaan drone oleh warga sipil meningkat pesat dengan penyajian total penjualan yang terus meningkat dengan cepat setiap tahun. Dengan meningkatnya kemungkinan penyalahgunaan Kendaraan Udara Tidak Berawak (UAV), kejahatan dalam penggunaan UAV menjadi lebih besar. Melalui analisis forensik data menggunakan forensik statis dan forensik hidup untuk memperoleh data yang memungkinkannya digunakan sebagai bukti digital. Untuk menggali informasi yang dapat digunakan sebagai bukti digital di UAV dan pengontrol, serta untuk mengetahui karakteristik bukti digital pada UAV. Hasil penelitian menunjukkan bahwa bukti digital pada UAV, smartphone yang digunakan sebagai pengontrol UAV memiliki peran yang sangat penting dalam penyelidikan. Temuan di pesawat memiliki persentase $50 \%$ dan kartu memori kamera dengan 16,6\%. DJI Phantom 4 Koordinat GPS tingkat lanjut selalu menyimpan data dalam LOG penerbangan; data selalu disimpan bahkan ketika mode penerbangan digunakan tidak menggunakan sinyal GPS untuk stabilitas. Karena DJI Phantom 4 Advanced selalu menggunakan GPS pada penerbangan, file, gambar atau video yang ditangkap oleh kamera memiliki koordinat lokasi GPS terbaik ke metadata di dalamnya.
\end{abstract}

Kata kunci: UAV, GPS, Flight Data, Forensik.

Abstract

In recent years, the use of drones by civilians is increasing rapidly by the presentation of total sales continued to increase rapidly every year. With the increasing possibility of Unmanned Aerial Vehicle (UAV) abuse, crime in the use of UAVs to be larger. Through forensic analysis of data using static forensic and live forensic to obtain data that allows it to be used as digital evidence. To dig up information that could be used as digital evidence in the UAV and controllers, as well as to know the characteristics of digital evidence on a UAV. The results showed that digital evidence on a UAV, the smartphone is used as a controller UAV has a very important role in the investigation. The findings in aircraft has a percentage of $50 \%$ and a camera memory card with $16.6 \%$. DJI Phantom 3 Advanced GPS coordinates always store data in flight LOG; the data is always stored even when the flight mode is used does not use GPS signals to stability. Due to DJI Phantom 3 Advanced always use GPS on flights, file, image or video captured by the camera has the best GPS location coordinates to the metadata therein.

Keywords: UAV, GPS, Flight Data, Forensic.

\section{Pendahuluan}

Kendaraan Udara Tak Berawak (UAV) atau disebut juga drone, adalah pesawat kecil tanpa pilot. Sekarang ini adalah yang paling banyak digunakan dalam militer dan para penggemar hobi fotografi/videografi. Dalam beberapa tahun terakhir, penggunaan drone oleh warga sipil meningkat pesat, sampai disebutkan oleh House of Lords Inggris bahwa 2014 adalah "Tahun drone" [1].

Majalah Forbes pada tahun 2015 menulis di distribusi situs Web penjualannya satu pemegang merek dagang drone dari awal hingga sekarang. Pada awal penjualan pada 2009 hingga 2010, penyajian pendapatan tahunan lebih dari $50 \%$ dari keseluruhan penjualan berada di Amerika Utara. Apalagi pada tahun 2011 total presentasi penjualan tahunan meningkat hingga 280\%, sedangkan penjualan di Amerika Utara hanya sekitar 30\% dari total penjualan. Presentasi dari total penjualan terus meningkat pesat setiap tahun, penjualan drone pada tahun 2020 diperkirakan akan menyentuh \$ 2,28 Miliar [2].

Drone bekerja dengan dua bagian; yang pertama adalah drone itu sendiri dan sebuah pengontrol yang berfungsi untuk mengendalikan drone. Pada beberapa jenis drone, sudah tidak ada lagi yang membutuhkan pengontrol untuk mengendalikan pesawat. Drone jenis ini menggunakan pemancar GPS yang dipasang pada pengguna, jadi ketika ini diaktifkan, pesawat akan secara otomatis mengikuti arahan dari orang-orang yang menggunakan remote control. Drone seperti ini 
ILKOM Jurnal Ilmiah Volume 11 Nomor 2 Agustus 2019

Terakreditasi peringkat 3 SK. No. 28/E/KPT/2019

memiliki banyak sensor, yang berguna untuk menjaga drone tetap aman dari lingkungan sekitarnya saat terbang mengikuti pengguna [3].

Bukti digital yang dapat diambil dari tubuh drone dan pengontrolnya adalah ID drone itu sendiri, lokasi di mana drone pernah terbang, gambar atau video diambil ketika drone diterbangkan, log memperbarui perangkat lunak yang digunakan. Sementara pengontrol dapat ditemukan dalam bentuk penyimpanan bukti digital dari gambar atau video yang diambil menggunakan drone, mencatat lokasi penggunaan drone, perangkat lunak yang digunakan untuk mengendalikan drone, ID drone terhubung [4].

Ranah penelitian ini adalah mengumpulkan informasi dan melakukan analisis bukti digital yang terkandung pada drone sepanjang pengontrolnya dengan menggunakan forensik statis dan live forensics dengan upaya membantu melengkapi informasi tentang aktivitas forensik yang menggunakan GPS pada drone.

\section{Metode}

Untuk mendukung percobaan pada penelitian ini, perangkat keras, dan perangkat lunak yang diperlukan digunakan tercantum di bawah ini:

- DJI Phantom 4 Advanced dan controller.

- Smartphone Android dan PC.

- DJI GO untuk Android

- FTK Imager

- Datcon V3

- Photome

Untuk mensimulasikan skenario yang dibuat dari penggunaan drone, sedangkan skenario penggunaan UAV dalam penelitian ini akan digambarkan sebagai Gambar 1.

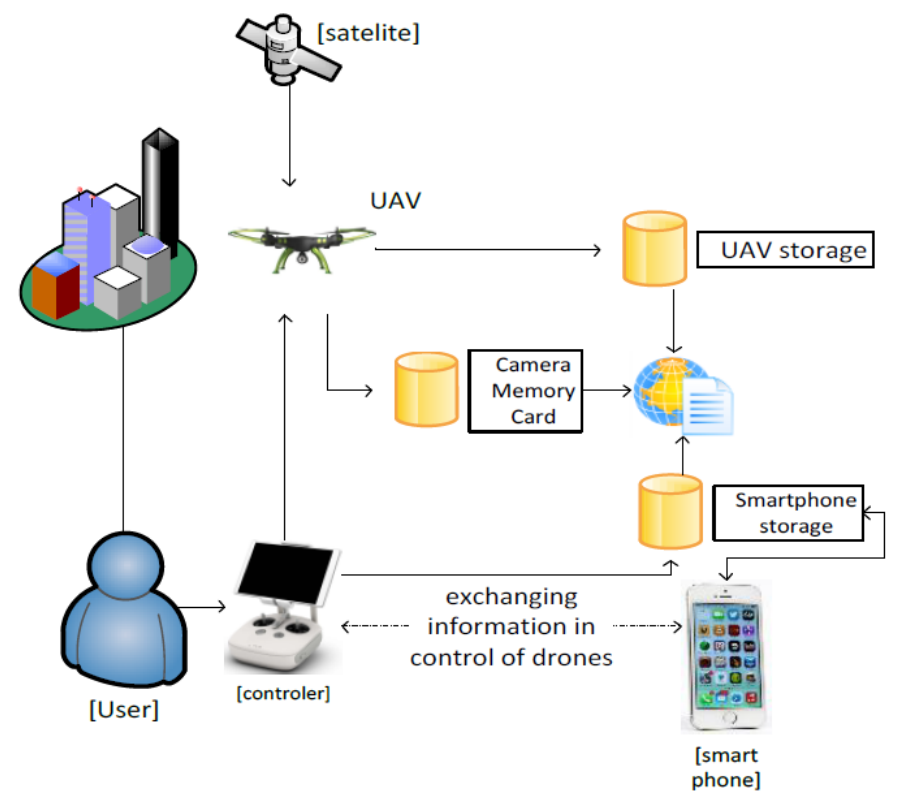

Gambar 1. Skenario Penerbangan UAV

Skenario yang dirancang dalam penelitian ini dioperasikan drone untuk melakukan beberapa penerbangan dengan mode terbang yang berbeda dan mengambil gambar dan video di situs. Di setiap lokasi ini, ketika sensor navigasi yang diterbangkan di dalam drone menerima data lokasi dari satelit GPS dan GLONASS yang kemudian disimpan ke dalam database di drone. controller dan smartphone sebagai ground station digunakan sebagai pengontrol dan penerima sinyal video pesawat. Semua data yang diterima dari ground station UAV kemudian disimpan dalam basis data pada telepon pintar sebagai penerima sinyal[5][6]. 
ILKOM Jurnal Ilmiah Volume 11 Nomor 2 Agustus 2019

Terakreditasi peringkat 3 SK. No. 28/E/KPT/2019

\section{Hasil dan Pembahasan}

\subsection{Skenario}

Skenario yang digunakan dalam penelitian ini melalui beberapa aktivitas yang dilakukan menggunakan tiga mode berbeda selama penerbangan. Penerbangan pertama dilakukan dengan menggunakan P-mode (Positioning), yang dalam mode ini menggunakan GPS dan Vision Position System bekerja bersama. Dalam mode ini, ada tiga keadaan yang secara otomatis dipilih oleh DJI Phantom 4 Advanced berdasarkan pada kekuatan sinyal GPS dan Vision Positioning Sensor [7][8]. Adapun bentuk tiga keadaan:

- P-GPS: GPS Positioning dan Vision sensor tersedia dalam mode ini UAV menggunakan GPS untuk posisi itu.

- P-OPTI: Pemosisian Visi tersedia tetapi kekuatan sinyal GPS tidak memadai, dalam mode ini hanya menggunakan Sistem Pemosisian Visi UAV untuk posisi tersebut.

- P-ATTI: Sinyal GPS dan Vision Positioning tidak tersedia dalam mode ini hanya menggunakan barometer UAV untuk posisi, jadi hanya ketinggian yang dapat distabilkan.

\subsection{Akuisisi}

Proses akuisisi UAV dilakukan dalam tiga bagian, yang pertama dari pesawat yang digunakan selama penerbangan. Media penyimpanan kamera kedua digunakan dalam penerbangan. Apalagi yang ketiga ada pada controller atau stasiun bumi yang ada di sini adalah menggunakan smartphone Lenovo A7000.

Proses akuisisi dalam penyimpanan pesawat dan kartu memori yang ditemukan di pesawat dilakukan dengan cara fisik (sektor per sektor atau salinan bit-stream) sehingga hasil pencitraan akan sama dengan bukti fisik. File gambar disimpan dengan ekstensi.dd.

\subsection{Analisis}

1) Ekstraksi Bukti GPS

Dalam penelitian ini, ditemukan bahwa log yang berisi data informasi GPS memiliki ekstensi file DAT pada penyimpanan pesawat dan file dengan ekstensi .txt pada smartphone. Log data pada UAV penyimpanan dengan ekstensi DAT yang berisi informasi GPS yang disimpan di direktori /root/FLY019.DAT. Sedangkan hasil log pada smartphone dengan ekstensi .txt disimpan di direktori /root/DJI/dji.pilot/FlightRecord/DJIFlightRecord_2019-08- 29_ [16-25-49] .txt.

\section{a) P-mode (position)}

Dalam log yang ditemukan di pesawat dianalisis dengan membaca file FLY019.log.txt hasil dari penggunaan aplikasi DatCon pada file FLY019.DAT dikenal mode penerbangan, lokasi titik asal direkam, dan durasi penerbangan, untuk lebih detail dapat dilihat pada gambar 2 .

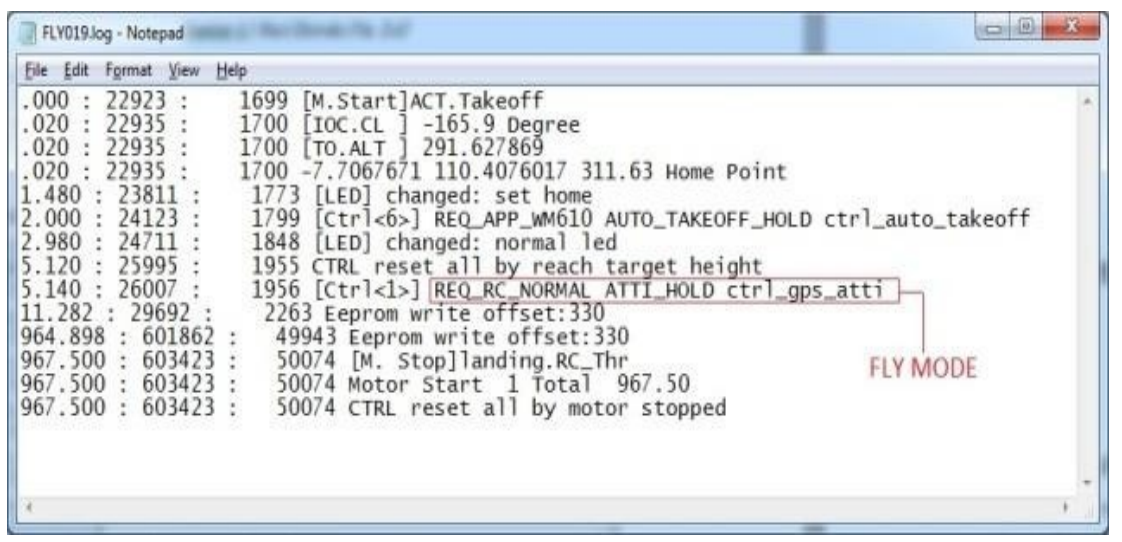

Gambar 2. Log File Fly019.Dat

Dalam log file yang ditemukan media penyimpanan UAV dapat dilihat berbagai kumpulan koordinat dan jalur penerbangan yang dilakukan dengan cara mengunggah file log FLY019.DAT ke aplikasi berbasis web yang beralamatkan di https://www.mapsmadeeasy.com/ untuk mengolah dan menampilkan kedalam daftar dalam bentuk csv. Contoh data log GPS dapat dilihat dalam tabel 1 dibawah ini. 
ILKOM Jurnal Ilmiah Volume 11 Nomor 2 Agustus 2019 Terakreditasi peringkat 3 SK. No. 28/E/KPT/2019

Tabel 1. Sample Koordinat GPS

\begin{tabular}{lll}
\hline Longitude & Latitude & Altitude $(\mathbf{m})$ \\
\hline 110.407602 & -7.70653814 & 292.17404 \\
110.407602 & -7.70676250 & 291.9357 \\
110.407603 & -7.70676682 & 378.17572 \\
110.407603 & -7.70676783 & 400.34015 \\
110.407607 & -7.70676827 & 408.8675 \\
110.407606 & -7.70676712 & 387.056 \\
\hline
\end{tabular}

b) A-mode (Attitude)

Dalam log yang ditemukan di pesawat, dianalisis dengan membaca file FLY021.log.txt hasil penggunaan aplikasi DatCon pada file FLY021.DAT dikenal mode penerbangan, lokasi titik asal direkam, dan durasi penerbangan. Untuk lebih jelasnya bisa dilihat pada Gambar 3.

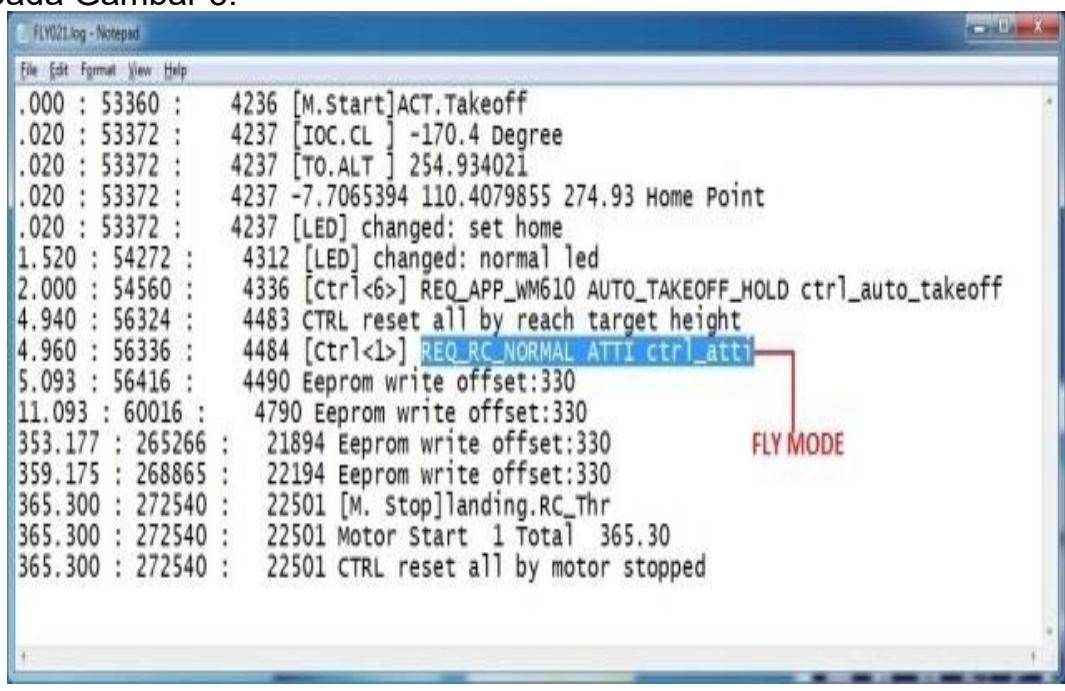

\section{Gambar 3. Log File Fly020.Dat}

Untuk jalur penerbangan dengan mode ini masih dapat ditemukan menggunakan proses yang sama seperti sebelumnya. Ini dengan mengunggah file log FLY021.DAT ke aplikasi berbasis web yang beralamat di https://www.mapsmadeeasy.com/ untuk mengolah dan menampilkan kedalam daftar dalam bentuk csv. Contoh data log GPS dapat dilihat dalam tabel 2 di bawah ini.

Tabel 2. Sample Koordinat Gps

\begin{tabular}{lll}
\hline Longitude & Latitude & Altitude $(\mathrm{m})$ \\
\hline 110.407974 & -7.70653814 & 256.1733 \\
110.407877 & -7.70667488 & 280.66656 \\
110.407814 & -7.70676682 & 279.22858 \\
110.407825 & -7.70669853 & 281.3734 \\
110.407841 & -7.70661924 & 282.16977 \\
110.407827 & -7.70658926 & 282.1325 \\
\hline
\end{tabular}

c) F-mode (Function)

Untuk jalur penerbangan dengan mode ini masih dapat ditemukan menggunakan proses yang sama seperti sebelumnya. Ini dengan mengunggah file log FLY021.DAT ke aplikasi berbasis web yang beralamat di https://www.mapsmadeeasy.com/ untuk mengolah dan menampilkan kedalam daftar dalam bentuk csv. Contoh data log GPS dapat dilihat dalam tabel 3 di bawah ini. 
ILKOM Jurnal Ilmiah Volume 11 Nomor 2 Agustus 2019 Terakreditasi peringkat 3 SK. No. 28/E/KPT/2019

Tabel 3. Sample Koordinat Gps

\begin{tabular}{lll}
\hline Longitude & Latitude & Altitude $(\mathbf{m})$ \\
\hline 110.407070 & -7.70664311 & 271.31238 \\
110.407070 & -7.70667488 & 277.22327 \\
110.407069 & -7.70676682 & 277.67554 \\
110.407073 & -7.70669853 & 286.21893 \\
110.407111 & -7.70661924 & 286.2421 \\
\hline
\end{tabular}

2) Konversi Bukti GPS

Analisis lebih lanjut yang dilakukan adalah mengonversi file log selain yang terdapat dalam penyimpanan pesawat, kartu memori kamera, dan smartphone. Metode ini dilakukan dengan membaca file yang berisi informasi lokasi metadata atau GPS; file mungkin termasuk gambar, video, dan lainnya. Dalam proses ini, setelah file gambar yang diambil dalam UAV penyimpanan, dan smartphone ditemukan. File yang diekspor menggunakan aplikasi FTK Imager untuk membaca metadata di dalamnya dengan menggunakan aplikasi PhotoMe. Secara rinci, informasi pada koordinat file .dd GPS dapat dilihat pada Gambar 5.

\begin{tabular}{|c|c|c|c|c|}
\hline & & & & $\Delta$ \\
\hline Field & Content & Tag-ID & Tag Name & Data Format \\
\hline GPS tog version & Version 3.2 & 0000 & GPSVersionid & BYTE(4) \\
\hline North or South Latitude & South lattude & 0001 & GPSLatitudeRef & $\operatorname{ASCII}(2)$ \\
\hline Lattude & $7^{\circ} 42^{\prime} 21.647^{\prime \prime}$ & 0002 & GPSLatitude & RATIONAL(3) \\
\hline East or West Longtude & East longitude & 0003 & GPSLongitudeRef & $\operatorname{ASCII}(2)$ \\
\hline Longitude & $110^{\circ} 2427.4888^{\circ}$ & 0004 & GPSLongtude & RATIONAL(3) \\
\hline Altitude reference & Sea level & 0005 & GPSAltitudeRef & BYTE \\
\hline Altitude & $328.963 \mathrm{~m}$ & 0006 & GPSAltitude & RATIONAL \\
\hline
\end{tabular}

Gambar 4. Log File Fly020.Dat

Dari hasil konversi file dari media penyimpanan, baik drone maupun controller Investigators dapat memperkuat bukti yang diperoleh dari informasi GPS yang ditemukan dalam kasus kejahatan dalam penggunaan drone.

\subsection{Hasil Analisis}

Setelah melalui proses ekstraksi dan konversi bukti digital GPS, tahap selanjutnya yang dilakukan hadir dalam bentuk presentasi. Presentasi forensik digital dalam serangkaian kegiatan yang dilakukan oleh para ahli forensik dalam menunjukkan temuannya di pengadilan untuk menjelaskan sebuah kasus dalam membantu para hakim dalam membuat keputusan. Penyajian bukti digital GPS untuk bentuk yang berbeda. GPS disajikan secara visual menggunakan Google maps atau aplikasi yang relevan dalam menyajikan koordinat lokasi.

1) Data pada Smartphone

Presentasi penelitian ini dibuat dengan menggunakan alamat situs web https://airdata.com/ untuk menampilkan informasi penerbangan yang disimpan dalam file log DJIFlightRecord_2019-06-31_[17-00-34] .txt terkandung dalam smartphone. Untuk lebih jelasnya, informasi penerbangan dapat dilihat pada Gambar 6. 
ILKOM Jurnal Ilmiah Volume 11 Nomor 2 Agustus 2019

Terakreditasi peringkat 3 SK. No. 28/E/KPT/2019

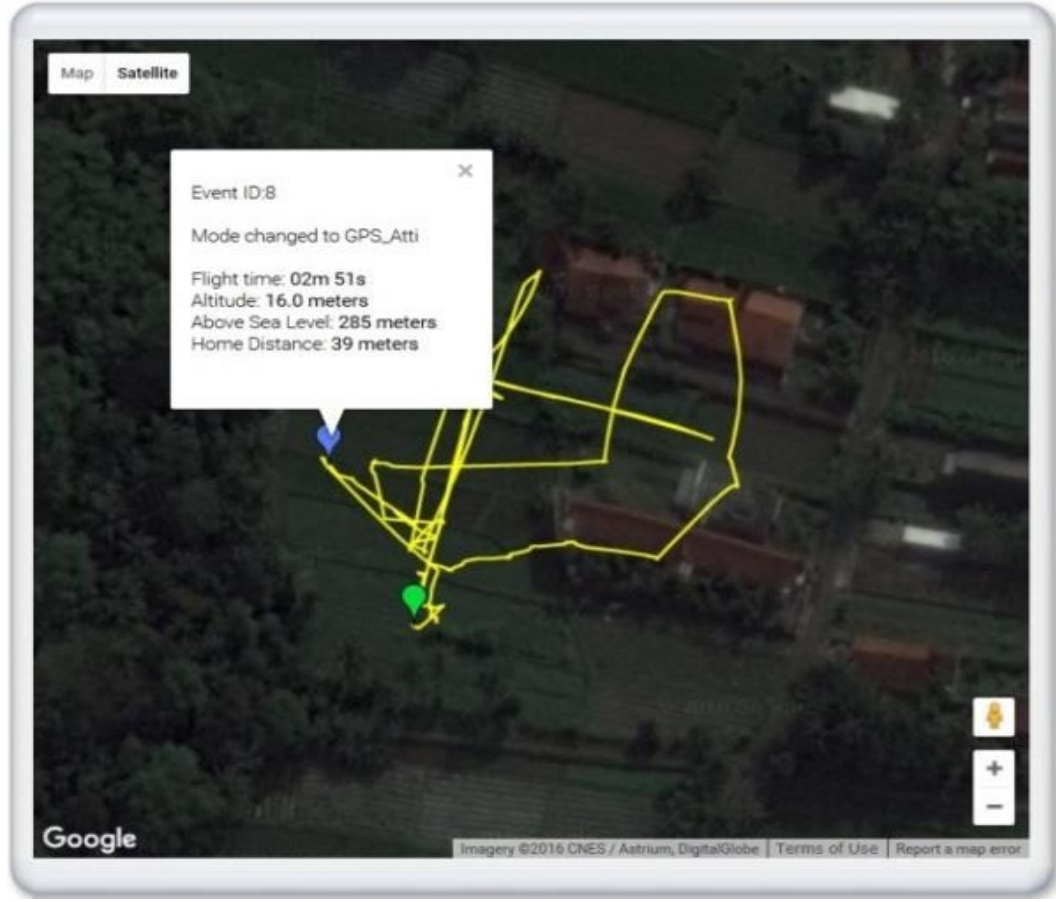

Gambar 5. Log File Fly020.Dat

Penyajian hasil UAV bisa diketahui jalur penerbangannya. Di titik hijau "F-mode" dieksekusi dan fungsi Follow me on UAV work, dan pada titik-titik biru ketinggian 16meter dan sejauh 39meter dari titik home, mode $\mathrm{F}$ dimatikan dan diubah menggunakan mode $\mathrm{P}$.

2) Log data pada storage UAV

Untuk mencatat file dengan ekstensi DAT yang terkandung dalam penyimpanan UAV dapat menggunakan https://www.mapsmadeeasy.com/log_viewer alamat situs di lokasi presentasi, jalur penerbangan, kecepatan, ketinggian, dan berbagai informasi bermanfaat sebagai bukti

UAV. Untuk lebih detail log presentasi data FLY021.DAT dapat dilihat pada Gambar 7.

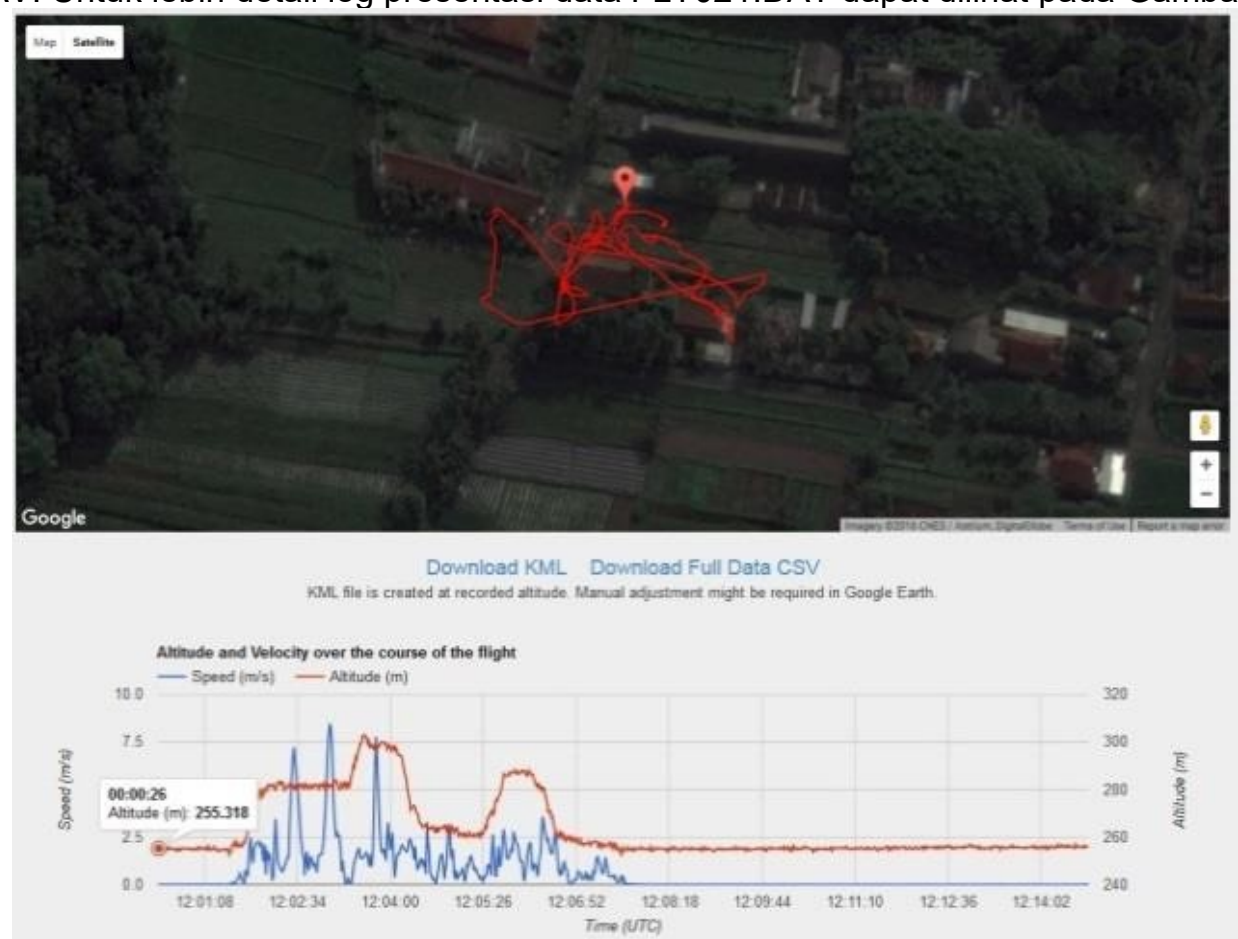

Gambar 6. Log File Fly020.Dat

DOI: http://dx.doi.org/10.33096/ilkom.v11i2.444.152-158 
ILKOM Jurnal Ilmiah Volume 11 Nomor 2 Agustus 2019

Terakreditasi peringkat 3 SK. No. 28/E/KPT/2019

Dalam data log dengan ekstensi DAT, informasi yang ditampilkan masih tidak kaya jika dibandingkan dengan informasi yang diperoleh dari log pengontrol (smartphone) yang digunakan untuk mengontrol penerbangan.

3) Hasil Konversi gambar pada UAV

Untuk informasi GPS, presentasi hasil file gambar konversi yang diambil oleh kamera UAV, gunakan aplikasi Google Maps. Pada Gambar 6 dapat dilihat hasil koordinat lokasi yang terdapat dalam file metadata org_a8ccc30f7ce0c44f_1472617871000.jpg Hasil presentasi dapat diketahui koordinat lokasi $-7,706890,110,4082 \overline{5} 5$. Lokasi foto yang diambil adalah di Sumberrejo mertoyudan, Kabupaten Magelang.

\section{Kesimpulan dan saran}

Data GPS yang berpotensi digunakan sebagai bukti digital selalu disimpan dalam log sistem UAV yang terkandung pada penyimpanan pesawat, kartu memori, dan smartphone. Data GPS selalu menyimpan informasi bahkan jika sistem menggunakan mode penerbangan UAV tanpa menggunakan GPS. Dari penelitian ini, telah diketahui potensi seluruh bukti digital yang berisi informasi pada perangkat UAV. Persentase bukti digital yang ditemukan dalam UAV penyimpanan memiliki $50 \%$ dari keseluruhan temuan dan pada kartu memori memiliki $16,6 \%$ dari keseluruhan temuan. Sementara sebagian besar bukti digital ditemukan ada pada penyimpanan smartphone yang digunakan sebagai pengontrol UAV. Dalam media penyimpanan smartphone ditemukan hampir seluruh informasi yang dapat diperoleh dari UAV.

\section{Daftar Pustaka}

[1] G. Horsman, "Unmanned aerial vehicles: A preliminary analysis of forensic challenges," Digit. Investig., vol. 16, pp. 1-11, 2016.

[2] H. Shao, "Drone Overlord Frank Wang On DJl's Milestones, Miscarried GoPro Partnership \& Corporate Espionage," Forbes Asia, 2015.

[3] J. D. Barton, "Fundamentals of Small Unmanned Aircraft Flight," Johns Hopkins Apl Tech. Dig., vol. 31, no. 2, pp. 132-149, 2012.

[4] A. J. Kerns, D. P. Shepard, J. A. Bhatti, and T. E. Humphreys, "Unmanned Aircraft Capture and Control Via GPS Spoofing," J. F. Robot., vol. 31, no. 4, pp. 617-636, 2014.

[5] A. Arbelet, "Garmin satnavs forensic methods and artifacts: An exploratory study School of Computing," no. August, 2014.

[6] Sukriadi and Y. Prayudi, "Analysis of Digital Evidence of Global Positioning System (GPS) On Android Smartphone," Kns\&I Stikom, no. 11, 2014..

[7] K. Hartmann and C. Steup, "The vulnerability of UAVs to cyber attacks - An approach to the risk assessment," Cyber Confl. (CyCon), 2013 5th Int. Conf., pp. 1-23, 2013.

[8] T. Jiang, J. Li, and K. Huang, "Longitudinal parameter identification of a small unmanned aerial vehicle based on modified particle swarm optimization," Chinese J. Aeronaut., vol. 28, no. 3, pp. 865-873, 2015. 